\title{
Pathogenesis of postantibiotic diarrhoea caused by Clostridium difficile: an in vitro study in the rabbit intestine
}

\author{
S GUANDALINI, A FASANO, M MIGLIAVACCA, M C VERGA, \\ P MASTRANTONIO GIANFRILLI, A FERRARA, M ALESSIO, \\ B MALAMISURA, P GALATI, A PANTOSTI, AND A RUBINO
}

From the Department of Pediatrics, 2nd School of Medicine, University of Naples, Italy, Istituto Superiore di Sanita, Rome, Italy, and Institute of Pathology, Veterinary School, University of Naples, Italy

SUMmary To elucidate the pathophysiological changes leading to postantibiotic diarrhoea caused by Clostridium difficile and its cytotoxin, oral ampicillin was given to rabbits, and jejunal, ileal, and caecal segments of those that developed diarrhoea were investigated in vitro. The rabbits that, in response to treatment, harboured Clostridium difficile in their colonic lumen were studied, and the results expressed according to the presence or absence of Clostridium difficile and/or its cytotoxin. Thus, we refer to either $\mathrm{CD}+$ or $\mathrm{CD}-$ segments. The influx of glucose, phenylalanine, glycylphenylalanine, and lysine across the brush border of jejunum and ileum of $\mathrm{CD}+$ segments was severely impaired, while only slightly blunted in $\mathrm{CD}-$. No significant change was detected in the influx of glutamic acid in the jejunum of all treated animals and in the CD- ilea. Morphologic damage in ileum and caecum of $\mathrm{CD}+$ was also more evident than in $\mathrm{CD}-$. Transepithelial ion transport across short circuited ileal mucosa $(\mathrm{CD}+$ and $\mathrm{CD}-$ ) revealed secretory changes in $\mathrm{Cl}$ net transport that were more marked in $\mathrm{CD}-$. We conclude that: (1) Clostridium difficile may also colonise the upper intestinal tract, where it induces morphological and functional damage, severely impairing nutrient absorption; and (2) the ileum contributes to the diarrhoea caused by CD even when the micro-organism is confined to the more distal gut by showing moderate impairment of nutrient absorption and marked electrolyte secretion.

The administration of antibiotics, particularly by the oral route, may be accompanied by gastrointestinal complaints, the most severe of which is diarrhoea. It is well known that Clostridium difficile (CD) may mediate such a complication by inducing a colitis of variable severity; the most widely recognised form being pseudomembranous colitis, an entity occurring both in adults and in children. ${ }^{2}$ Although it is well known that $C D$ releases toxic factors (two of which have been extensively investigated - toxin $\mathrm{A}$ or enterotoxin and toxin $\mathrm{B}$ or cytotoxin), ${ }^{3}$ the pathophysiological changes actually ensuing after $C D$

Address for correspondence: Prof Stefano Guandalini, Dipartimento di Pediatria, 2a Facolta'di Medicina, Via S. Pansini, 5, 80131, Napoli, Italy.

Received for publication 17 November, 1987. development caused by antibiotic treatment and leading to diarrhoea have not been well characterised.

The aim of our study was therefore to investigate the changes in structure and/or function arising in several intestinal segments in animals receiving antibiotic treatment that developed $\mathrm{CD}$ and diarrhoea.

\section{Methods}

ANIMALS

Male New Zealand white rabbits fed ad libitum were used throughout the study. They received oral ampicillin $(40 \mathrm{mg} / \mathrm{kg}$ body weight/day) in a single daily dose for 10 days or until diarrhoea developed. Of the 25 rabbits so treated, three did not develop 
diarrhoea. Of the remaining 22 (in which diarrhoea occurred after a mean of $5 \cdot 2$ days), eight died quite soon after its onset and could therefore not be studied.

The remaining 14 , as well as six untreated, control rabbits, were killed and underwent the following investigations.

\section{MICROBIOLOGY AND IDENTIFICATION OF}

CLOSTRIDIUM DIFFICILE AND ITS CYTOTOXIN

Cultures for enterobacteria and Clostridia (CD and Clostridium spiroforme) were performed on the stools of all animals, including controls, before treatment and on the intestinal contents of jejunum, ileum and caecum after death.

Cultures for Clostridia were carried out in an anaerobic cabinet using Columbia blood agar after ethanolic shock and CCFA (Oxoid) for CD. The identification was done by biochemical reactions and gas chromatographic analysis. ${ }^{4}$ All samples were also examined for cytotoxic effects on monolayers of $\mathrm{CHO}, \mathrm{Hep} 2$, and Vero Cells using 96 well microtitre plates. ${ }^{5}$ Clostridium difficile antitoxin (Virginia Polytechnic Institute) and Clostridium perfringens iota antitoxin were used to neutralise respectively $C D$ and Clostridium spiroforme cytotoxins. Although we did not search for toxin A, the detection of toxin B can be assumed to signal the simultaneous presence of toxin $A$, as no strain of $C D$ has yet been isolated that would produce either toxin alone. ${ }^{3}$

\section{HISTOLOGICAL STUDIES}

Fragments of different intestinal segments were taken after death and fixed in $10 \%$ formol saline. The samples were then embedded in paraffin wax, sectioned and stained with haematoxylin and eosin for examination by light microscopy.

\section{NUTRIENT INFLUX STUDIES}

These were done according to a published procedure. ${ }^{6}$ Briefly, $10 \mathrm{~cm}$ segments of jejunal or ileal mucosa were preincubated in lucite influx chambers, allowing four adjacent portions of the mucosal side (each having a surface area of $1.12 \mathrm{~cm}^{2}$ ) to be bathed only on the luminal side with a bicarbonate Ringer's solution having the following composition (in $\mathrm{mmol} / \mathrm{l}): \mathrm{Na}+, 141 ; \mathrm{K}+5 ; \mathrm{Ca}++, 1 \cdot 25 ; \mathrm{Mg}++, 1 \cdot 1$; $\mathrm{Cl}-, 61 ; \mathrm{SO} 4--, 30 \cdot 5 ; \mathrm{HCO}_{3}-, 25 ; \mathrm{H}_{2} \mathrm{PO}_{4}-, 0 \cdot 3$; $\mathrm{HPO}_{4}--, 1.65$; and mannitol, $30 \cdot 5$; and gassed with $5 \% \mathrm{CO}_{2}$ in $\mathrm{O}_{2}$ yielding a $\mathrm{pH}$ of $7 \cdot 4$, at $37^{\circ} \mathrm{C}$ for 20 minutes. Incubations then followed by substituting a solution of identical composition but with the presence of the substrate being tested, labelled with $14 \mathrm{C}$, and $3 \mathrm{H}$-Inulin as a marker of the extracellular space. After $45-50 \mathrm{sec}$, incubation was stopped by quickly removing the test solution and adding $0.3 \mathrm{M}$ mannitol. Each piece was then punched out, blotted on filter paper, homogenised in $10 \%$ trichloroacetic acid, and centrifuged. Aliquots of supernatants were assayed for radioactivity in a liquid scintillation counter. Calculations were done according to the described method.

\section{ION TRANSPORT STUDIES}

These were done as previously described, ${ }^{7}$ using Ringer solution. Two pieces of stripped ileum and two pieces of stripped caecum from each animal were mounted in Ussing chambers. Transepithelial electrical potential difference (PD), total electrical conductance $(\mathrm{Gt})$, and short circuit current (Isc) were measured as previously described. Oppositely directed, unidirectional transepithelial fluxes of sodium and chloride from mucosa to serosa (m-s) and from serosa to mucosa (s-m) were measured under short circuit conditions using $22 \mathrm{Na}$ and $36 \mathrm{Cl}$ as previously described. Ji net $=\mathrm{Ji} \mathrm{m}-\mathrm{s}-\mathrm{Ji} \mathrm{s}-\mathrm{m}$; Ji net different from 0 represents active transport of the ion species $i$. JR net is calculated as: JR net $=\mathrm{Isc}-\mathrm{JNa}$ net $+\mathrm{JCl}$ net.

\section{CYCLIC NUCLEOTIDE STUDIES}

These determinations were carried out according to the method of Harper and Brooker, ${ }^{8}$ using kits by Amersham. Immediately after death, samples from ileum and caecum, stripped from muscle and serosal layers, were frozen for subsequent determinations. After thawing, they were processed according to the previously described procedure. Results are expressed as picomoles of cAMP or cGMP/mg mucosal protein (protein content was determined by the method of Lowry et al). ${ }^{9}$

\section{STATISTICAL ANALYSIS}

All results are expressed as mean (SE). The significance of the differences has been calculated using the Student's $t$ test for either paired or unpaired variates.

\section{Results}

ISOLATION OF CLOSTRIDIUM DIFFICILE Clostridium difficile was not detected in any of the stool samples collected before the beginning of therapy from every rabbit, or from the intestinal contents of any of the six control animals. Among the animals receiving ampicillin, CD and/or its cytotoxin were found in the colon of 13 animals (in the colon of the 14th rabbit another Clostridial strain C spiroforme, was detected. Results of studies on this animal are not included here). In three of such animals. $\mathrm{CD}$ and/or its cytotoxin were found throughout the gut; in five rabbits, they were detected only in ileum and colon, and in the remain- 
Table 1 Detection of clostridia in rabbits developing diarrhoea after treatment with ampicillin

\begin{tabular}{lllll}
\hline Animalno & Species & Jejunum & Ileum & Colon \\
\hline 1 & Cdifficile & + & + & + \\
2 & Cdifficile & + & + & + \\
3 & Cdifficile & + & + & + \\
4 & Cdifficile & - & + & + \\
5 & Cdifficile & - & + & + \\
6 & Cdifficile & - & + & + \\
7 & Cdifficile & - & + & + \\
8 & Cdifficile & - & + & + \\
9 & Cdifficile & - & - & + \\
10 & Cdifficile & - & - & + \\
11 & Cdifficile & - & - & + \\
13 & Cdifficile & - & - & + \\
14 & Cspiroforme & - & - & + \\
\hline
\end{tabular}

The + and - signs mean the detection of clostridia and/or their cytotoxin $(+)$ or lack of them $(-)$ in the indicated intestinal segment.

ing five animals only in the colon (Table 1). Accordingly, we will hereafter refer to $\mathrm{CD}+$ and CD - segments, meaning small bowel segments in which $\mathrm{CD}$ and/or its cytotoxin were either detected $(\mathrm{CD}+)$ or not $(\mathrm{CD}-)$.

\section{NUTRIENT INFLUX MEASUREMENTS}

Results showing the rates of transport of glucose, phenylalanine, glycyl-phenylalanine, lysine and glutamic acid from the mucosal medium into the epithelium of either jejunum or ileum of control, $\mathrm{CD}+$ and $\mathrm{CD}-$ segments are reported in Figs 1 and 2 , respectively. It appears that in the jejunum, with the exception of glucose which is moderately inhibited, the absorptive transport of all tested nutrients is, at the concentrations tested, well preserved in $\mathrm{CD}-$ areas, while it appears clearly blunted in CD + segments: only the influx of glutamic acid is in fact not significantly inhibited.

In the ileum, most nutrients are less effectively taken up by the mucosa of all diarrhoeic ampicillin treated rabbits. The uptake of all tested nutrients but glycyl-phenylalanine and glutamic acid was in fact

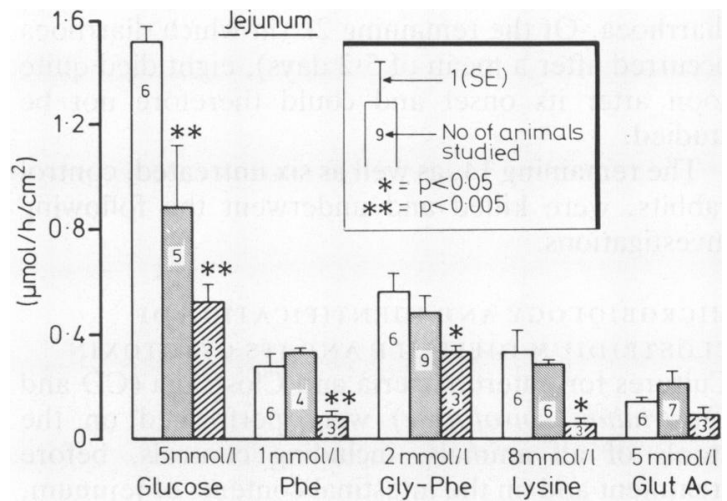

Fig. 1 Nutrient influx in the jejunal mucosa of control ( $\square)$, $C D-(\mathbf{\square})$, and $C D+(\mathbb{Z})$ segments. Bars represent influx of different nutrients at concentration shown in the figure.

Number of animals studied is given in parentheses. Brackets indicate 1 (SE). ${ }^{*} p<0 \cdot 05 ;{ }^{* *} p<0 \cdot 005$.

significantly blunted in CD - segments; while that of all tested nutrients except glycyl-phenylalanine was impaired in areas where $C D$ was detected. The rather higher degree of mucosal injury seen in CD+ ileum provides a reasonable morphologic support for such observation (see below).

\section{TRANSEPITHELIAL ION FLUXES}

\section{Ileum}

The transport of $\mathrm{Na}$ and $\mathrm{Cl}$ across stripped, short circuited mucosa of control, $C D-$ and $C D+$ ilea was also measured. Results are reported in Table 2. In controls, the m-s flux for both ions is bigger by about $2 \mu \mathrm{Eq}$ than the s-m corresponding flux, thus resulting in net absorption of both $\mathrm{Na}$ and $\mathrm{Cl}$.

In contrast, in CD - ileum, while there was no statistically significant change in $\mathrm{Na}$ transport, $\mathrm{JCl}$ $\mathrm{m}$-s was significantly reduced, leading to the development of a $\mathrm{Cl}$ net secretory state.

The changes observed in the $\mathrm{CD}+$ ileal segments differ from the latter: first of all, a marked, significant

Table 2 Transepithelial fluxes in the ileum

\begin{tabular}{|c|c|c|c|c|c|c|c|c|c|}
\hline & $J^{N a} m s$ & $J^{\mathrm{Na}} s m$ & $J^{\mathrm{Na}} n e t$ & $J^{\mathrm{Cl}} m s$ & $J^{\mathrm{Cl}} \mathrm{sm}$ & $J^{\mathrm{cl}}$ net & $I s c$ & $J^{\mathrm{R}} n e t$ & $G t$ \\
\hline Controls $[n=6]$ & $15 \cdot 02(1 \cdot 62)$ & $12 \cdot 75(1 \cdot 17)$ & $2 \cdot 27(1 \cdot 19)$ & $7 \cdot 95(1 \cdot 16)$ & $5 \cdot 77(1 \cdot 08)$ & $2 \cdot 18(0 \cdot 9)$ & $1 \cdot 28(0 \cdot 9)$ & $1 \cdot 19(1 \cdot 0)$ & $33 \cdot 24(2 \cdot 5)$ \\
\hline$C D-[n=5]$ & $10 \cdot 77(1 \cdot 14)$ & $11.20(2.97)$ & $-0.43(2 \cdot 19)$ & $4.36(0.77)$ & $7 \cdot 31(0 \cdot 71)$ & $-2.95(1.75)$ & $2 \cdot 86(0 \cdot 36)$ & $0.34(1.35)$ & $34.90(3.56)$ \\
\hline $\mathrm{p}\left[{ }^{*}\right]$ & NS & NS & NS & $<0 \cdot 05$ & NS & $<0.025$ & NS & NS & NS \\
\hline$C D+[n=8]$ & $19 \cdot 11(2 \cdot 41)$ & $17 \cdot 24(2 \cdot 55)$ & $1.87(1.05)$ & $10 \cdot 06(1.67)$ & $11.07(2.66)$ & $-1.01(1.02)$ & $2 \cdot 12(0 \cdot 25)$ & $-0.76(0.85)$ & $46 \cdot 95(3 \cdot 18)$ \\
\hline $\mathrm{p}[\dagger]$ & NS & NS & NS & NS & NS & $<0.05$ & NS & NS & $<0.01$ \\
\hline $\mathrm{p}[\ddagger]$ & $<0.05$ & NS & NS & $<0.05$ & NS & NS & NS & NS & $<0 \cdot 05$ \\
\hline
\end{tabular}

Values are mean (SE) for the number of animals reported in square brackets. Fluxes and Isc are in $\mu \mathrm{Eq} / \mathrm{h} / \mathrm{cm}^{2} ; \mathrm{Gt}$ is in $\mathrm{mmol} / \mathrm{cm}^{2}$. *significance of differences calculated comparing CD - with control rabbits; † tsignificance of differences calculated comparing CD + with control rabbits; $\ddagger$ significance of differences calculated comparing $C D+$ with $C D-$ rabbits. 
Table 3 Transepithelial fluxes in the caecum

\begin{tabular}{|c|c|c|c|c|c|c|c|c|c|}
\hline & $J^{\mathrm{Na}} m-s$ & $J^{\mathrm{Na}} s-m$ & $J^{\mathrm{Na}_{\mathrm{a}}} n e t$ & $J^{C l} m-s$ & $J^{\mathrm{Cl}} s-m$ & $J^{\mathrm{Cl}}$ net & $I s c$ & $J^{\mathrm{R}}$ net & $G t$ \\
\hline Control $[n=4]$ & $8 \cdot 34(0 \cdot 58)$ & $6 \cdot 38(0 \cdot 45)$ & $+1.96(0.47)$ & $7 \cdot 12(1 \cdot 02)$ & $5 \cdot 57(0 \cdot 76)$ & $+1 \cdot 55(0.24)$ & $2 \cdot 76(0 \cdot 13)$ & $2 \cdot 35(1 \cdot 54)$ & $18 \cdot 90(2 \cdot 2)$ \\
\hline$C D+[n=9]$ & $6.30(0.49)$ & $5 \cdot 56(0 \cdot 89)$ & $+0 \cdot 74(0.34)$ & $3 \cdot 20(0 \cdot 48)$ & $5.99(0.59)$ & $-2 \cdot 79(1.13)$ & $4.67(0.44)$ & $1 \cdot 14(1 \cdot 37)$ & $19 \cdot 31(0.77)$ \\
\hline $\mathrm{p}$ & $<0.05$ & NS & NS & $<0.005$ & NS & $<0.05$ & $<0.025$ & NS & NS \\
\hline
\end{tabular}

Values are mean (SE) for the number of animals reported in square brackets. Fluxes and Isc are in $\mu \mathrm{Eq} / \mathrm{h} / \mathrm{cm}^{2} ; \mathrm{Gt}$ is in $\mathrm{mmol} / \mathrm{cm}^{2}$.

increase in Gt (reflecting the enhanced mucosal permeability to electrolytes) is seen. As a result, all measured unidirectional fluxes are also enhanced. The modifications in net electrolyte transport are minor, as no net secretion developed: JNa net is unaffected, $\mathrm{JCl}$ net is abolished, because of an increment in its s-m component. Thus, in $\mathrm{CD}+$ as compared with $\mathrm{CD}$ - ilea, an increase in tissue ion permeability and a lesser secretory shift in $\mathrm{NA}$ and $\mathrm{Cl}$ net transport is seen.

\section{Caecum}

Table 3 reports the results obtained when measuring the steady state transepithelial fluxes of $\mathrm{Na}$ and $\mathrm{Cl}$ across the short circuited mucosa of the caecum. Here too, in controls, $\mathrm{Na}$ and $\mathrm{Cl}$ are actively absorbed, to a similar extent. The magnitude of unidirectional fluxes is consistently lower than in the ileum (as pointed out by the lower $\mathrm{Gt}$ ). In the CD+ caecal mucosa, $\mathrm{Na}$ and $\mathrm{Cl}$ transport rates are profoundly affected, with their $\mathrm{m}$-s fluxes being impaired. Such decrease (which is larger for $\mathrm{Cl}$ ) makes net $\mathrm{Na}$ absorption no longer significant and

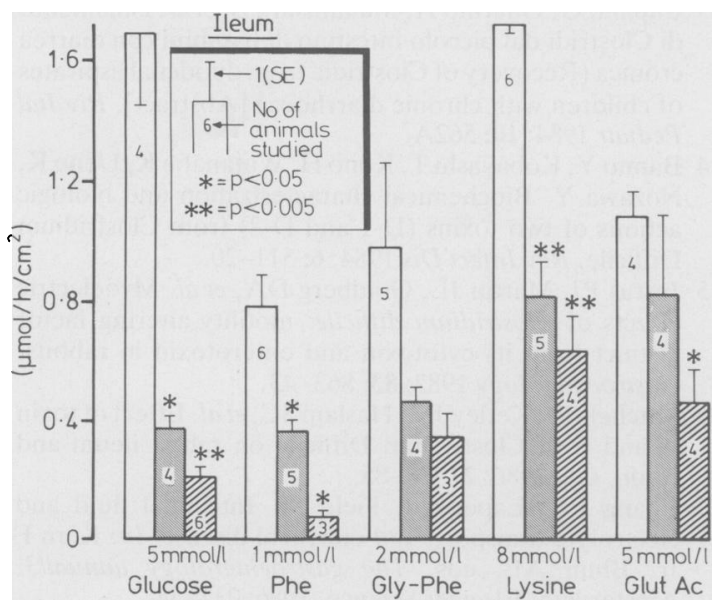

Fig. 2 Nutrient influx in the ileal mucosa of control ( $\square$ ), $C D-(\square)$, and $C D+(\mathbb{Z})$ segments. Bars represent influx of different nutrients at concentration shown in the figure. Number of animals studied is given in parentheses. Brackets indicate $1(S E) .{ }^{*} p<0.005 ;{ }^{* *} p<0.001$. results in the development of a net secretory state for $\mathrm{Cl}$ transport. A sizeable rise in Isc accompanies such changes.

HISTOLOGY

Sections from $\mathrm{CD}+$ and $\mathrm{CD}-$ ileum show morphologic damage, with the more severe changes (mucosal atrophy with severe villous blunting, crypt hyperplasia and mononuclear infiltration) being seen in the intestinal segments harbouring $C D$ and/or its cytotoxin. In CD + caecum, severe dysepithelisation with disruption of gland architecture, mucus depletion, oedema, haemorrhagic effusions, and inflammatory cell infiltration is also evident.

CYCLIC NUCLEOTIDES

As the observed secretory changes in electrolyte transport could be theoretically attributed to increases in tissue concentrations of cAMP and cGMP, we measured their concentrations in ileal and caecal mucosa. We found no increase in either cyclic nucleotide in any of the tested conditions: in the ileum, cAMP averaged 95 (5)\% of the control value in $\mathrm{CD}-$ segments and $112(15) \%$ in $\mathrm{CD}+$; cGMP averaged $108(7) \%$ of control, while CD $+90(10) \%$. In the caecum, cAMP in CD + was $69(20) \%$ of control, and cGMP was $98(4) \%$.

\section{Discussion}

Diarrhoea not uncommonly follows an antibiotic course: in its most serious presentation, this complication may be because of a colitis bearing the typical pseudomembrane formation - that is, pseudomembranous colitis. Such long known complication of antibiotic therapy has been shown in recent years to be due to the Gram positive anaerobe CD." Although it is known that CD releases at least four toxic factors," the pathophysiological changes that they mediate and that ultimately lead to diarrhoea (particularly where no pseudomembranous colitis is found) are not well defined. In this regard, the present study is the first report investigating, in an animal model in vitro, the intestinal alterations occurring after the induction of $\mathrm{CD}$ - mediated diarrhoea in vivo. 
The major conclusions that can be drawn can be summarised as follows: (1) The administration of antibiotics may be followed by CD colonisation not confined to the large bowel, but extending to the upper gut. Such data are consistent with already reported scanty observations of $\mathrm{CD}$ detection in the duodenal juice in $\operatorname{man}^{1213}$ and improves our understanding of the pathogenesis of diarrhoea caused by $\mathrm{CD}$ : in fact, the absorptive transport of nutrients was found to be severely affected in all the small bowel segments where $C D$ was detected. Also, the $C D+$ ileum showed a highly significant increase in tissue permeability and the abolition of $\mathrm{Cl}$ absorption. (2) Small intestinal segments devoid of CD also show diarrhoegenic pathophysiological changes: in fact, while morphology and nutrient transport appear relatively spared, net $\mathrm{Cl}$ secretion develops. (3) The presence of $\mathrm{CD}$ in the caecum induces secretory changes in $\mathrm{Cl}$ transport and a rise in Isc.

The changes that we observed can be conceivably traced to the known virulence factors of $C D$ : namely, toxin A ('enterotoxin'), toxic B ('cytotoxin') (both reviewed in ref 11), a heat labile toxin, ${ }^{14}$ and a 'motility altering factor'. ${ }^{15}$ Although the aim of our work was not focused on determining which factor caused which change, we may, however, speculate that toxin A (which was recently shown to be the most active one $)^{16}$ is responsible for the morphologic injury throughout the intestine and for the enhanced permeability in the ileum; on the other hand, the secretory changes seen in electrolyte transport in ileum and caecum, may be ascribed again to toxin A, as well as to the more recently described heat labile toxic factor. As for the secretory changes seen in GI segments proximal to sites of $\mathrm{CD}$ colonisation, they might be attributed to local mediators of inflammation, known to have a role in intestinal secretion, ${ }^{17} 18$ to the possible adsorption of $\mathrm{CD}$ toxin to more proximal tracts, or to the development of other enterotoxigenic bacteria. The latter possibility is, however, less likely, as we did not detect known enterotoxigenic bacteria (data not shown) in any of the sampled GI tracts, nor did we find increases in cyclic nucleotide levels that might have expected to occur as a result of stimulation by the known heat stable or heat labile enterotoxins.*

\footnotetext{
*Since the first submission of this manuscript, the paper by Mitchell et al 'The effects of Clostridium difficile toxins and purified toxin A on stripped rabbit ileal mucosa in Ussing chambers' appeared in J Med Microbiol 1987; 23: 199-204. The paper describes, in the same animal model used by us, the effects of CD toxins on ion transport, with findings that are in many ways very similar to those reported by us. These results therefore: (1) add further support to our observations which unlike those of Mitchell et al, were obtained in the intestine of animals that had previously been exposed, in vivo, to the development of the infection and; (2) indicate that toxin $\mathrm{A}$, as we speculated in the discussion is responsible for the observed changes in $\mathrm{CD}+$ segments.
}

\section{References}

1 Bartlett JG. The pseudomembranous enterocolitides.
In: Sleisenger J, Fordtran JS, eds. Gastrointestinal disease 1978; 106: 1715-29.

2 Viscidi RP, Bartlett JG. Antibiotic-associated pseudomembranous colitis in children. Pediatrics 1981; 67: 381-6.

3 Lyerely DM, Wilkins TD. Characteristics of the toxins of Clostridium difficile. In: Borriello SP, ed. Antibioticassociated diarrhea and colitis. Boston, Den Haag: Martinus Nijhoff, 1984: 89-102.

4 Anaerobe laboratory manual. 4th ed. Blacksburg, Virginia: Virginia Polytechnic Institute, 20461.

5 Chang TW, Loverman M, Bartlett JG. Cytotoxin assay in antibiotic associated colitis. J Infect Dis 1979; 140: 765-70.

6 Rubino A, Field M, Schwachman H. Intestinal transport of amino acid residues of dipeptides. Influx of the glycine residue of glycyl-proline across mucosal border. J Biol Chem 1971; 246: 3452-8.

7 Field M, Fromm D, McColl I. Ion transport in rabbit ileal mucosa. I. $\mathrm{Na}$ and $\mathrm{Cl}$ fluxes and short-circuit current. Am J Physiol 1971; 220: 1388-96.

8 Harper JF, Brooker G. Femtomole sensitive radioimmunoassay for cyclic AMP and cyclic GMP after $2^{\prime} 0$ acetylation by acetic anhydride in aqueous solution. J Cyclic Nucleotide Res 1975; 1: 207-18.

9 Lowry OH, Rosebrough NJ, Farr AL, Randall RJ. Protein measurement with the Folin phenol reagent. J Biol Chem 1951; 193: 265-75.

10 Bartlett JG, Moon TW, Chang TW, Taylor N, Onderdonk AB. Role of Clostridium difficile in antibiotic-associated pseudomembranous colitis. Gastroenterology 1978; 75: 778-82.

11 Borriello SP. Bacterial infections: Clostridium Difficile and gastrointestinal disease. Curr Opinion Gastroenterol 1985; 1: 145-9.

12 Taylor RH, Borriello SP, Taylor AJ. Isolation of Clostridium Difficile from the small bowel. $\mathrm{Br} \mathrm{Med} \mathrm{J}$ 1981; 283: 412.

13 Capano G, Guarino A, Malamisura B, et al. Isolamento di Clostridi dal piccolo intestino di bambini con diarrea cronica (Recovery of Clostridia from duodenal aspirates of children with chronic diarrhoea) [Abstract]. Riv Ital Pediatr 1984; 10: 562A.

14 Banno Y, Kobayashi T, Kono H, Watanabe K, Ueno K, Nozawa $\mathrm{Y}$. Biochemical characterization and biologic actions of two toxins (D-1 and D-2) from Clostridium Difficile. Rev Infect Dis 1984; 6: 511-20.

15 Justus PJ, Martin JL, Goldberg DA, et al. Myoelectric effects of Clostridium difficile: motility-altering factor distinct from its cytotoxin and enterotoxin in rabbits. Gastroenterology 1982; 83: 863-43.

16 Mitchell TJ, Ketley JM, Haslam SC, et al. Effect of toxin $A$ and $B$ of Clostridium Difficile on rabbit ileum and colon. Gut 1986; 27 : 78-85.

17 Chang EB, Lapook J, Field M. Intestinal fluid and electrolyte transport, and diarrheal disease. In: Kern F $\mathrm{Jr}$, Blum $\mathrm{AL}$, eds. The gastroenterology annual/3. Amsterdam: Elsevier Science, 1986: 211-34.

18 Kimberg DV, Field M, Gershon E, Henderson A. Effects of prostaglandins and cholera toxin on intestinal mucosal cyclic AMP accumulation: Evidence against an essential role for prostaglandin in the action of toxin. J Clin Invest 1974; 53: 941-9. 